\title{
SEXISMO LINGUÍSTICO E O PROCESSO DE MANUALIZAÇÃO: A PRESENÇA DO FEMININO E DA MULHER NA LÍNGUA ${ }^{1}$
}

\section{LINGUISTIC SEXISM AND THE PROCESS OF MANUALIZATION: \\ THE PRESENCE OF FEMININE AND WOMAN ON THE LANGUAGE}

\author{
Dantielli Assumpção Garcia \\ Universidade Estadual do Oeste do Paraná, Cascavel, PR, Brasil
}

Resumo: Neste trabalho, da perspectiva teórica da Análise de Discurso em articulação com a História das Ideias Linguísticas, analisaremos as condiçôes de produção do processo de manualização (PUECH, 1998) de uma linguagem não sexista, feminizada, refletindo acerca da produçáo de manuais no contexto brasileiro, francês e espanhol.

Palavras-Chave: Manualização; Linguagem não sexista; Feminização; Mulher; Gênero.

Abstract: In this work, from the theoretical perspective of Discourse Analysis in articulation with the History of Linguistic Ideas, we will analyze the production conditions of the manualization process (PUECH, 1998) of a feminist non-sexist language, reflecting on the production of manuals in the Brazilian context, French and Spanish.

Keywords: Manualization; Non-sexist language; Feminization; Woman; Genre.

\section{Um pouco sobre manualizaçáo}

"O destino de uma mulher é ser mulher" (LISPECTOR, 1977, p. 100)

Motivados pelo pensamento de Clarice Lispector e filiados à Análise de Discurso de linha francesa (PÊCHEUX, 1997) em articulação com a História das Ideias Linguísticas, explicitaremos, neste texto, alguns

\footnotetext{
1 Este trabalho fez parte de minha pesquisa de Pós-Doutorado $A$ manualização do saber linguístico e a constituição de uma linguagem não sexista realizada junto ao Programa de PósGraduação em Letras da Universidade Estadual do Oeste do Paraná, sob a supervisão do Prof. Dr. Alexandre Sebastião Ferrari Soares (PNPD-CAPES). Uma versão inicial deste texto foi apresentada em The Fourteenth International Conference On The History of The Language Sciences, ICHoLS XIV, Paris, 2017.
} 
resultados de nossa pesquisa de Pós-Doutorado, a qual teve como objetivo central, mobilizando as noçóes de instrumento linguístico, gramatização (AUROUX, 1992) e manualização (PUECH, 1998), analisar diferentes materiais (dicionários, manuais, cartilhas, guias), publicados em diferentes países (Brasil, Espanha, França), os quais constituem um saber sobre uma "linguagem náo sexista", entendida como a materializaçáo do gênero gramatical feminino no funcionamento linguístico. Essa materialização constitui-se como um processo, dito pelos manuais, de feminização das línguas. Neste artigo, analisaremos as condiçôes de produção que possibilitaram a elaboraçáo/circulação desses manuais de linguagem não sexista/feminizada ${ }^{2}$ no contexto brasileiro, francês e espanhol.

Como afirmamos em Garcia (2017, p. 192), os manuais analisados não se voltam para uma discussão em torno da construção/identificação sociocultural de gênero. $O$ gênero com o qual esses instrumentos linguísticos trabalham é o gênero enquanto categoria morfológica, dicotomizada entre masculino e feminino. Esses instrumentos retomam um saber linguístico acerca do gênero, questionando o uso do masculino como genérico e mostrando que esse gesto acaba por apagar a presença da mulher, isto é, do gênero feminino na língua.

Em nossa pesquisa em torno dessa feminização, encontramos os seguintes manuais que propóem um uso não sexista da linguagem e a representação do gênero gramatical feminino nos usos linguísticos ${ }^{3}$ :

- Guía del lenguaje para el ámbito de la empresa y el empleo (CUNILL, 2011).

- Guía del lenguaje para el ámbito de la cultura (CUNILL, 2010).

- Guía del lenguaje para el ámbito del deporte (CUNILL, 2009).

- Guía del lenguaje para el ámbito de la salud (CUNILL, 2009).

2 Para análise dos manuais, especificamente, indicamos os trabalhos: Garcia e Sousa (2016), Garcia (2017).

3 Essa pesquisa foi feita por meio da ferramenta Google, na qual digitamos os termos (em português, francês e espanhol): linguagem sexista, feminização da língua, manuais, masculino como genérico. A partir desses termos, chegamos a esses instrumentos linguísticos que listamos e que estão disponíveis para a consulta na rede. Nos textos que tomam também a questão do sexismo linguístico e a feminização da língua como objetos aparecem outros, mas, às vezes, os desconsideramos, pois esses instrumentos não são encontrados disponíveis online, no espaço digital (critério usado por nós para a escolha dos nossos objetos). 
- Guía del lenguaje para el ámbito educativo (CUNILL, 2008).

- Las profesiones de la A a la Z (CUNILL, 2006).

- Hablamos de leyes (MARTIN, CUNILL, 2008).

- Nombra: la representación del femenino y el masculino en el lenguaje (CUNILL, 1995).

- Language et sexisme (PREFECTURE DE LA REUNIÓN, s.d.).

- L'égalité s'écrit : guide de rédaction épicéne (BUREAU DE L'ÉGALITE ENTRE LES FEMMES ET LE HOMMES, 2007).

- Petit guide pour un language non sexiste (ORBAN, 2012).

- Femme, j'écris ton nom... Guide d'aide à la feminasation des noms de métiers, titres, grades et fonctions (CENTRE NATIONAL DE LA RECHERCHE SCIENTIFIQUE, INSTITUT NATIONAL DE LA LANGUE FRANÇAISE, 1999).

- Manual para o uso náo sexista da linguagem: o que bem se diz, bem se entende (SECRETARIA DE POLÍTICAS PÚBLICAS PARA AS MULHERES DO GOVERNO DO ESTADO DO RIO GRANDE DO SUL, 2014).

A partir desse material de análise, nosso objetivo foi buscar compreender como esse saber sobre uma linguagem feminizada e náo sexista de gênero passou a circular na sociedade e a formular um dizer que materializa a presença do (gênero) feminino na língua, gênero esse considerado pelos diferentes manuais como apagado por causa de um machismo que afeta o modo como os diferentes instrumentos que funcionam na sociedade (gramáticas e dicionários) documentam uma língua.

Os manuais são considerados nesta nossa pesquisa como um instrumento tecnológico (AUROUX, 1992) e $^{4}$ como um produto

\footnotetext{
4 Auroux (1992) indica serem os dicionários e as gramáticas (acrescentamos os manuais) instrumentos linguísticos que prologam a fala dos sujeitos que fazem uso de uma língua. Nas palavras do autor: "A gramática não é uma simples descrição da linguagem natural, é preciso concebê-la também como um instrumento lingüístico: do mesmo modo que um martelo prolonga o gesto da mão, transformando-o, uma gramática prolonga a fala natural e dá acesso a um corpo de regras e de formas que não figuram junto na competência de um mesmo locutor. Isto é ainda mais verdadeiro acerca dos dicionários: qualquer que seja minha competência lingüística, não domino certamente a grande quantidade de palavras que figuram nos grandes dicionários monolíngues" (AUROUX, 1992, p. 69, grifos do autor).
} 
sociocultural de vulgarização de um saber sobre a língua (PUECH, 1998), os quais, amparados em leis, decretos, funcionam atendendo a demandas feministas que anseiam por uma posição legitimada à mulher. Nos manuais, é possível perceber como os saberes linguísticos se expóem, se difundem e apontam para um funcionamento da sociedade. A proposta dos manuais é promover uma cultura náo sexista em que a equidade de gênero (aqui especificamente o gênero gramatical, dicotomizado em masculino e feminino) seja marcada nos usos linguísticos (GARCIA, 2017, p. 193).

Os manuais, vistos como instrumentos linguísticos ${ }^{5}$, participam do processo de gramatização ${ }^{6}$ de uma língua, descrevendo-a e instrumentalizando-a. Nesses instrumentos, o sexismo linguístico é colocado em evidência e contradito enquanto norma a ser seguida, surgindo em seu lugar a proposta de feminizar a língua, ou seja, marcar o gênero feminino nos substantivos, adjetivos, artigos. Ademais, os manuais são tomados aqui como um "objeto sociocultural claramente identificado pela aproximação/ diferenciação com/de outros produtos socioculturais do mundo científico" (PUECH, 1998, p. 15-16). Os manuais diferenciam, por exemplo, de um dicionário, por buscarem, filiados a um discurso instrucional, dizer como se deve ou não usar a língua, "operacionalizando com as regras gramaticais, os manuais apresentam o funcionamento da língua sobre a qual falam e transmitem um saber acerca desta que passará a circular na sociedade" (GARCIA; SOUSA, 2016, p. 90).

Vejamos como os manuais: Femme, jécris ton nom... Guide d'aide à la féminisation des noms de métiers, titres, grades et fonctions; Guía del lenguaje para el ámbito educativo e Manual para o uso não sexista da linguagem: o que bem se diz bem se entende produzem um saber sobre os gêneros masculinos e

5 "A gramática não é uma simples descrição da linguagem natural, é preciso concebêla também como um instrumento lingüístico: do mesmo modo que um martelo prolonga o gesto da mão, transformando-o, uma gramática prolonga a fala natural e dá acesso a um corpo de regras e de formas que não figuram junto na competência de um mesmo locutor. Isto é ainda mais verdadeiro acerca dos dicionários: qualquer que seja minha competência lingüística, não domino certamente a grande quantidade de palavras que figuram nos grandes dicionários monolíngues" (AUROUX, 1992, p. 69, grifos do autor).

6 "Por gramatizaçáo deve-se entender o processo que conduz a descrever e a instrumentar uma língua na base de duas tecnologias que são ainda hoje pilares de nosso saber metalinguístico: a gramática e o dicionário" (AUROUX, 1992, p. 65, grifos do autor). Mais uma vez acrescentamos os manuais.

7 «du manuel comme objet socioculturel clairement identifiable par rapprochement/ différenciation (d')avec d'autres produits socioculturels du monde savant» (PUECH, 1998, p. 15-16). 


\section{femininos e propõem um uso desses na língua :}

\section{Le déterminant}

Dans tous les cas, la féminisation implique l'utilisation d'un déterminant féminin, pour les désignations simples comme pour les désignations complexes : la, une, cette... : la députée, une Juge, cette agente de change, la fondée de pouvolr...

\section{Noms se terminant au masculin par une voyelle}

Il s'agit de termes non suffixés, comme apprenti, architecte, gendarme, juge, ministre, vétérinaire, ou suffixés/composés (-é, -logue, -iste, etc.).

\section{2.a. Noms se terminant par -e}

8 - Votr supara, note 5.
p. 16.

La forme féminine est identique à la forme masculine (forme épicène) $)^{8}$.

ex. : une architecte, une astronaute, une cadre, une capitalne, une commissaire, une diplomate, la garde (des Sceaux), une garde-malade, une gendarme, une geologue, une inteme, une interprète, une juge, une mancuvre, une mintstre, une paysagiste, une peintre, une psychiatre, une vétérinalre...

Remarque : Certains noms ont été féminisés depuis longtemps à l'aide du suffixe -esse : hōtesse, mairesse, maitresse, pœétesse... Ce suffixe étant aujourd'hui senti comme désuet, voire dévalorisant, on a préféré ne plus y avoir recours. Seuls les emplois consacrés sont retenus (une hôtesse, une maitresse d'école) ; les emplois encore partiellement en usage sont toujours admis, à côté des formes épicènes proposées ou déjà concurrentes dans l'usage : une malre ou mairesse, une maitre ou maltresse (d'hôtel, de conférences, etc.), une poète ou poétesse...

Figura 1: Manuais

Fonte: Femme, j'écris ton nom...Guide d'aide à la féminisation des noms de métiers, titres, grades et fonctions $(1999$, p. 22)

8 Apresentamos somente um breve recorte desses instrumentos. 


\subsection{ORDEN DE APARICIÓN DE FEMENINO Y MASCULINO}

Una cuestión que se tiene que remarcar prioritariamente es que el orden de aparición de femenino y masculino es muy revelador, ya que denota una determinada jerarquización de hombres y de mujeres. A lo largo de los casos analizados es constante la anteposición al femenino del masculino (al estilo de las tarjetas de visita de las parejas heterosexuales, las tarjetas de los buzones de las mismas...). Evidentemente, este orden no responde a ninguna regla gramatical; por tanto, si lo que se quiere es dar un trato igualitario a las personas, lo mejor es irlo alternando.

Evidentemente, se ha de alternar el orden de aparición tanto en la utilización por escrito en cualquier ámbito de la institución escolar, como oralmente; en este último caso, tanto en el momento de explicar cualquier materia, como en el momento de hablar con el alumnado.

Figura 2: Manuais

Fonte: Guía del lenguaje para el ámbito educativo (2008, p. 57)

\section{Regras de concordância ou sintáticas}

Sempre, estejamos falando de casos comuns de dois ou nâo, utilizaremos os deferminantes femininos para acompanhar um ofício, profissâo ou cargo exercido por uma mulher e os deferminantes masculinos quando se trate de um homem.

\begin{tabular}{l|l}
\hline Nào empregar & Empregar \\
\hline Um fiscal & Uma fiscala \\
\hline Um patrão & Uma patroa \\
\hline Aquele cavaleiro & Aquela cavaleira \\
\hline O juiz & A juiza \\
\hline O industrial & A industrial \\
\hline
\end{tabular}

\section{Da mesma forma trataremos os adjetivos e os participios}

A juiza adjunta do tribunal / a segunda cavaleira da lista

O juiz adjunto do tribunal/ o segundo cavaleiro da lista

Figura 3: Manuais

Fonte: Manual para o uso não sexista da linguagem: o que bem se diz bem se entende

Como define Puech (1998, p. 15-16), a manualizaçáo consiste em um processo "pelo qual os saberes linguísticos se expóem e se difundem com fins operatórios de transmissão, apropriação, reinvestimento do que no produto propriamente dito" 9 . Como podemos observar, os manuais retomam um

9 «Il s'agit du processos par lequel les savoirs linguistiques s'exposent et se diffusent à des fins opératoires de transmission, appropiation, réinvestissement, plutôt que du produit à proprement parler» (PUECH, 1998, p. 15-16) 
saber linguístico acerca do gênero morfológico (masculino e feminino), questionando o uso do masculino como genérico, as possíveis hierarquias existentes na ordem da escolha entre masculino e feminino, o apagamento das profissóes no feminino. Esses instrumentos mostram como esse gesto (de masculinização) acaba por não dar visibilidade na língua à mulher. A proposta dos manuais é que o gênero feminino seja também marcado nos usos linguísticos para que, assim, haja uma equidade de gênero e não um sexismo na linguagem. A proposta dos Manuais, portanto, é feminizar a língua.

Para aprofundarmos um pouco a discussão sobre o processo de manualizaçáo de uma linguagem náo sexista/feminizada, retomemos as condiçóes de produção da emergência desses instrumentos, tomando como referência o contexto brasileiro, francês e espanhol.

\section{Uma língua feminizada e não sexista: suas condiçóes de produçáo}

"Não se nasce mulher, torna-se mulher" (BEAUVOIR, [1949] 1980, s.p.)

Tal como trabalhadas na Análise de Discurso, as condiçôes de produção compreendem os sujeitos e a situação. Em relação ao sujeito, não é considerado o sujeito empírico, mas sim a posiçáa sujeito projetada no discurso. Assim, as condiçôes de produçấo estão relacionadas aos lugares que os sujeitos aí ocupam; esses lugares, nos processos discursivos, funcionam como formações imaginárias. Nos manuais, diferentes são as imagens feitas para as mulheres e aos usos que essa faz da língua, para os homens e também para seus usos linguísticos na enunciação, para a sociedade e para seu sexismo linguístico. Nos manuais, ao marcar o gênero gramatical feminino, tornase a existência da mulher materializada na língua, nos usos dos possíveis sujeitos falantes.

Retomando as condiçôes de produção, em relação à situação, ressalta Orlandi (2002, p. 15) que esta pode ser pensada em sentido estrito e em sentido amplo: "em sentido estrito ela compreende as circunstâncias da enunciação, o aqui e o agora do dizer. No sentido lato, a situaçáo compreende o contexto sócio-histórico-ideológico, mais amplo". Para compreendermos os manuais, é necessário levarmos em consideração o contexto sóciohistórico-ideológico que possibilita a emergência e a circulação desses instrumentos em determinadas sociedades. 
Como mostramos em trabalho anterior (GARCIA, 2017), o uso náo sexista da linguagem, proposto ao manualizar-se uma língua feminizada, faz parte de um debate tanto político quanto linguístico, cuja "origem" se encontra principalmente nos movimentos feministas e de luta pelos direitos de igualdade entre gêneros. Nas palavras de Zoppi-Fontana (2015, p. 226227, grifos da autora), ele:

\begin{abstract}
Refere-se à denúncia dos efeitos sociais e ideológicos do uso de formas linguísticas (lexicais e morfológicas) que reproduzem e reforçam representaçóes preconceituosas das relaçóes de gênero na sociedade. Em geral, apontam-se formas lexicais com conotaçáo negativa usadas para referirse à identidade de gênero das pessoas (como, por exemplo, bicha, traveco, sapatão, cadela etc.), mas principalmente identificam-se formas de natureza gramatical, tocando na estrutura mesma do sistema linguístico, como é o caso da flexão de gênero morfológico das palavras e, mais especificamente, do uso consagrado do gênero masculino como forma genérica não marcada para referir a ambos os gêneros gramaticais. Também se inclui neste debate a resistência de nomes que referem a cargos e funçóes tradicionalmente ocupados por homens (por exemplo, a recente polêmica no Brasil sobre o uso do termo presidenta).
\end{abstract}

Os manuais buscam, de modo geral, dar visibilidade a algumas funçôes, profissóes realizadas pelas mulheres que, pelo uso da forma masculina como genérica, são silenciadas/censuradas na sociedade (pensemos, por exemplo, na discussão sobre a existência ou não do termo "presidenta" já pontuada por Zoppi-Fontana (2015). Ao didatizar e fazer circular um outro dizer sobre o gênero morfológico, no processo de manualização, feminização de uma língua, "os manuais produzem uma compreensão sobre as discriminaçóes de gênero que são materializadas na sociedade. Esses instrumentos fazem ecoar um saber linguístico que marca como não há uma equidade no tratamento (seja ele linguístico ou não) dado à mulher e ao homem na sociedade que faz uso de uma língua para se manifestar e se significar" (GARCIA, 2017, p. 195).

As discussōes acerca da feminização da língua estão longe de ser homogêneas. Elas caracterizam-se por uma pluralidade de posiçóes e mostram como o domínio das designaçóes (seja no masculino ou no feminino) concerne à posiçấo e à visibilidade dos sujeitos nas sociedades. Conforme Elmiger (2011, p. 72-73), feminizar a língua constitui uma tentativa de favorecer a igualdade entre os sexos, a partir da ideia de que a existência e a utilizaçáo de designaçóes femininas contribuem para promover 
na "realidade social" igualdade (de salário, de direitos, de oportunidades etc.). O que de fato nem sempre ocorre.

Iváńez (1996, p. 71) ressalta que a feminização de títulos, funçôes e profissôes (abrimos um parêntese para pontuar que as propostas dos manuais são, principalmente, dar visibilidade a profissões, títulos, funçôes desempenhadas também por mulheres, mas que, em geral, na língua, são usadas no masculino) oferece importantes exemplos de mudança linguística que uma língua pode sofrer. O ponto de partida dessa mudança é uma realidade de natureza sociológica: o acesso das mulheres ao domínio profissional ocupado majoritariamente por homens. Além de encontrar novas designaçôes que se relacionam às mulheres em exercício de novas profissóes, são constantes diversas reaçôes que condicionam a adoçáo sistemática da feminizaçáo da língua ou sua recusa. Dito de outro modo, parece-se que se identifica, geralmente, a feminização, nos dizeres de Iváñez (1996), com os discursos feministas, os quais pretendem, com os usos marcados, atribuir à mulher trabalhadora o status que lhe corresponde. O uso do masculino, como genérico, por exemplo, seria, nesses casos dos títulos, funçóes e profissóes, um reflexo do machismo, do sexismo na língua/linguagem e esconderia a participação da mulher na sociedade (nosso exemplo mais atual é o uso de "presidenta" e sua destituição do poder por meio de um golpe político-midiático. Nem na língua, nem na política parece poder a mulher pertencer).

Abbou (2011, p. 279) salienta que as motivaçôes da feminização e seus objetivos se sobrepóem entre os locutores, havendo três argumentos para tal feminização do idioma: a visibilidade (da mulher nos usos linguísticos), a desmasculinização do genérico e a língua como um lugar de luta política. Sendo, portanto, a feminizaçáo, para a autora (2011, p. 301), uma luta e uma ferramenta política, por isso que a produção dos manuais estará relacionada também a contextos de intervençôes governamentais/políticas.

É essa proposta de desmasculinizar a língua, feminizando-a, que temos nos manuais analisados nessa pesquisa. Como propomos neste artigo, exporemos brevemente as condiçóes de produçáo que permitiram a elaboração e a circulação desses manuais de linguagem não sexista. Tomamos o contexto brasileiro, francês e espanhol como objetos. Para essa discussão, retomamos alguns apontamentos feitos em Garcia e Sousa (2016) e Garcia (2017). 


\section{No contexto brasileiro}

A reivindicação pelo fim do tratamento discriminatório a mulheres levou à criação de leis e também à criação dos manuais ${ }^{10}$. No Brasil, tivemos em 1956 a Lei no 2.749, a qual normatizava sobre o gênero dos nomes designativos das funçôes públicas. Nela, podemos observar:

Art. $1^{\circ}$ Será invariavelmente observada a seguinte norma no emprego oficial de nome designativo de cargo público:

O gênero gramatical desse nome, em seu natural acolhimento ao sexo do funcionário a quem se refira, tem que obedecer aos tradicionais preceitos pertinentes ao assunto e consagrados na lexeologia do idioma. Devem, portanto, acompanhá-lo neste particular, se forem genericamente variáveis, assumindo, conforme o caso, eleição masculina ou feminina, quaisquer adjetivos ou expressôes pronominais sintaticamente relacionadas com o dito nome (LEI No 2.749, 1956).

Nessa lei, coloca-se em questão a relação entre gênero gramatical e sexo. Normatiza-se que, ocorrendo variação de gênero, essa deve ser marcada em virtude do sexo do indivíduo ao qual se faz referência. A lei não cita, como veremos no Projeto de Lei do Senado no 306, de 2005; nos Decretos no 49.994 e 49.995, de 27 de dezembro de 2012; e na Lei no 14.484, de 30 de janeiro de 2014, que o masculino é usado como genérico. Só marca que o sexo deve ser considerado ao colocar em funcionamento palavras de diferentes gêneros gramaticais. Náo há uma proposta de feminização da língua, como temos nas outras leis e projetos.

No Projeto de Lei no 306, de 2005, revoga-se a Lei no 2.749, de Abril

10 No Brasil, temos até o momento somente o seguinte instrumento linguístico produzido: Manual para o uso náo sexista da linguagem: o que bem se diz, bem se entende (Secretaria de Políticas Públicas para as Mulheres do Governo do Estado do Rio Grande do Sul, 2014). Esse é resultado dos Decretos no 49.994 e no 49.995 (de 27 de Dezembro de 2012) e a Lei no 14.484 (de 30 de janeiro de 2014), implantados no estado do Rio Grande do Sul. De acordo com Garcia e Sousa (2016, p. 93): "As propostas do Manual, amparadas na lei e nos decretos, estabelecem a utilizaçấo da linguagem inclusiva de gênero nos atos normativos, nos documentos e nas solenidades do Poder Executivo do Estado do Rio Grande do Sul. A mudança proposta pelo o Manual é para o âmbito da administração pública, pois considera que 'o Poder Executivo Estadual deve dar igual tratamento aos seus servidores, sejam eles homens ou mulheres, e ser impróprio a menção de denominaçôes masculinas ocupados por mulheres' (Decreto $n^{\circ}$ 49.995). Assim, espera-se com o Manual 'propiciar a linguagem inclusiva como política de igualdade de tratamento' (Decreto no 49.995). O Manual constitui-se com o objetivo de 'revisar' a linguagem usada na administração pública do Estado do Rio Grande do Sul, além de possibilitar a compreensão das 'discriminaçōes de gênero'”. 
de 1956, por considerá-la discriminatória. Há uma prescrição sobre o uso do gênero pela gramática, a qual as leis e os manuais buscam atualizar. Esses textos jurídicos formulam um outro dizer sobre esse fenômeno linguístico:

\begin{abstract}
Art. 50 A aplicação do disposto nesta Lei, ao lançar mão das instruçōes contidas em estudos, tratados ou descriçôes da língua portuguesa far-se-á sempre com a observância dos seguintes princípios:

I - obrigatória inclusão explícita dos gêneros feminino e masculino, com as respectivas concordâncias e pronomes, na designação geral ou particular dos cargos e assemelhados;

II - não predominância de um gênero sobre o outro, ainda que sustentada em uso do costume ou das gramáticas normativas;

III - uso dos dois gêneros para os casos de pluralizaçấo (PROJETO DE LEI No 306, 2005, p. 29541).
\end{abstract}

Aponta-se, no projeto de Lei, a predominância de um gênero sobre o outro, mesmo não se dizendo qual, pelo funcionamento de uma memória, sabemos que o gênero é o masculino. É em relação à predominância do masculino na língua que se lutará e reivindicará uma outra formulação, uma linguagem inclusiva, não sexista, feminizada. E é a essa proposta que os manuais buscarão atender. Conforme Garcia e Sousa (2016, p. 95):

[...] tal inscrição no âmbito do discurso do juridismo faz falar o quanto as relaçóes atuais são tensionadas pela desigualdade de acessos e de poder da mulher, e o quanto se pretende fazer, na ordem da língua e da lei, uma sutura do que está rasgado no social como ferida aberta e como impossibilidades para o feminino.

De acordo com Mari Perusso, Secretária da Assessoria Superior do Governador, no texto Por uma sociedade inclusiva, que compóe o Manual para o uso não sexista da linguagem: o que bem se diz, bem se entende (2014), debater a respeito de uma linguagem inclusiva, não sexista; falar sobre uma equidade de gênero, só é possível por termos, no governo atual, a participação feminina em postos de comando. Contudo, como mostramos em Garcia e Sousa (2016), a discussão sobre uma linguagem não sexista já estava sendo feita em outros governos, como no de Juscelino Kubitscheck, em 1956. Naquele momento, embora não se falasse em uma masculização da linguagem, já se apontava para a materialização da presença do feminino em denominaçôes de cargos públicos ${ }^{11}$. Também, no governo de Luis Inácio

11 É importante pontuar que as discussôes sobre a linguagem sexista no Brasil se darẫo 
Lula da Silva, foi apresentado em 2005 o Projeto de Lei no 306, no qual se define linguagem sexista e linguagem inclusiva de gênero e determinam-se formas de combater o sexismo na linguagem:

\footnotetext{
Com formulaçẫo da secretária Mari Perusso, há uma aparente militância em prol do governo atual em que uma mulher está [estava] no posto mais alto do comando do país. No manual, por essa fala da secretária, apagam-se projetos e leis que já legislaram sobre uma linguagem inclusiva de gênero. Parece que, por termos como presidenta uma mulher, as lutas e reivindicaçóes femininas/feministas são efetivamente atendidas e legitimadas, fato que não se dá, como podemos perceber pela discussão acerca da legalização do aborto - pauta tăo cara ao movimento feminista (GARCIA; SOUSA, 2016, p. 96).
}

Em síntese, no contexto brasileiro, por meio das leis, da circulação e do uso do Manual, há a tentativa de normatizar a vida social no âmbito do trabalho em órgãos públicos/governamentais. Assim, os cargos, as funçôes, os títulos, as profissóes devem apresentar também a forma feminina, marcando a presença da mulher nos usos da língua.

\section{No contexto espanhol}

No final da década de 1980, segundo Garcia e Sousa (2016), o Governo Espanhol impulsionou diversas discussóes acerca da linguagem sexista no âmbito administrativo. Em 1987, o Ministerio de Asuntos Sociales, por meio do Instituto de la Mujer, publicou o Plan para la igualdad de oportunidades de las mujeres, no qual se empreendeu a revisão dos textos reguladores para evitar usos e expressóes consideradas sexistas. O Instituto de la Mujer, em 1989, publicou outro documento, Propuestas para evitar el sexismo en el lenguaje, o qual também expunha a importância de materializar na língua as novas relaçóes sociais pelas quais as mulheres, principalmente, estavam passando. Em 1991, mais um documento é publicado, agora pela UNESCO - Recomendaciones para un uso no sexista del lenguaje - com a finalidade de produzir reflexôes acerca do que significa uma linguagem sexista. Em 22 de Março de 1995, por meio da Orden del Ministerio de Educación y Ciencia, apresenta-se uma proposta de se adequar as denominaçóes dos títulos acadêmicos ao gênero daquele que os obtenha, ou seja, não usar a forma

em âmbito público-administrativo. As propostas são para mudanças na forma como os órgãos governamentais dirigem-se a suas trabalhadoras e seus trabalhadores e falam sobre os cargos por elas e eles ocupados. 
masculina como genérica. Há ainda a Ley Orgánica 3/2007, de 22 de Marco, para a Igualdad efectiva de mujeres y hombres, que estabelece como critério de atuação de todos os poderes públicos a utilização de uma linguagem não sexista.

Semelhante ao Brasil, as discussôes sobre o sexismo na linguagem passam-se no âmbito da administração pública; contudo, com a participação de outras instituiçôes como a UNESCO. Também no contexto espanhol, a criação de leis auxiliará na produção de manuais sobre linguagem não sexista, feminizada em que o gênero feminino está incluso.

\section{No contexto francês}

Como já ressaltamos, a proposta de feminização da(s) língua(s) está relacionada à crítica feminista, tal como ela é manifestada a partir dos anos 1970, e também a decisões políticas, jurídicas e linguísticas. Conforme Elmiger (2011, p. 72), o caso da feminização (de textos oficiais) testemunha os esforços que uma comunidade está prestes a fornecer para modificar sua utilizaçáo da língua e, consequentemente, para valorizar o status das mulheres na sociedade por meio da linguagem.

Diversos são os países e regióes francófonas que desenvolveram meios para propor o uso de língua feminizada. Québec ${ }^{12}$, por exemplo, é a primeira região francófona a tomar decisóes políticas em relação à feminização. Desde o fim dos anos 1970, aparecem as primeiras recomendaçóes que respondem a uma demanda lexical: em 1976, um ministro canadense consulta "L'Office de la Langue Française" a fim de decidir se é necessário feminizar as designaçóes de trabalho ou favorecer as formas epicenas, como em inglês. Essa questão teve uma primeira resposta em 1979 no relatório Pour les Québécoises: egalité et indépendence du Conseil du Statut de la femme que, a partir de uma recomendação de "L'Office de la Langue Française", foi a favor da "utilização de formas femininas em todos os casos possíveis" Durante os anos 1980, outras publicaçóes aparecem, como: Titres et fonctions au féminin: essai d'orientation de l'usage (editado por Office de la Langue Française, 1986). Como afirma Elmiger (2011, p. 73-74), se os primeiros textos se preocupavam essencialmente com a formação dos nomes

12 Os comentários sobre como cada país pensou e atuou a respeito da feminização da língua foram retirados de Elmiger (2011, p. 73-76).

13 "l'utilisation des formes féminines dans tous les cas possibles" (Bouchard et. al., 1999, p. 08, apud Elmiger, 2011, p. 73). 
femininos (no aspecto lexical da feminização), a ideia de feminizar todos os nomes comuns de pessoas de acordo com o contexto ("feminização do discurso") aparece relativamente cedo: o guia Pour un genre à part entière aborda diversos pontos relacionados à feminização de textos e ressalta como melhor soluçáo a utilizaçáo da dupla forma: feminina e masculina. Outros guias são também publicados por instituiçóes públicas ou privadas no Québec. Por exemplo: Au féminin (1991), editado por L'Office de la Langue Française, ou À Juste Titre (1994).

Já na França, como ressalta Elmiger (2011), a questáo (unicamente lexical) das designaçóes femininas é inicialmente tratada por uma comissão de terminologia. A comissão é presidida por Benoîte Groult e tem como finalidade feminizar os nomes das profissóes e dos trabalhos. Desde sua criaçáo em 1984, a "Comissão Groult" esteve sujeita a ataques violentos provenientes do domínio público e também da Academia Francesa. Os resultados de seus trabalhos são publicados na Circulaire du 11 Mars 1986 relative à la féminisation des noms de métier, fonction, grade ou titre, segundo Elmiger (2011, p. 74-75), em um momento crucial da vida política francesa, isto é, alguns dias antes da mudança de governo que faz chegar ao poder Jacques Chirac ao posto de Primeiro Ministro.

Para Elmiger (2011, p. 74-75), o novo governo, "de direita", que sucedeu um governo "de esquerda", náo "se sentiu obrigado" a adotar o que preconizava a circular. Dez anos depois, em uma outra mudança de governo, a questão da feminização é retomada em uma nova circular (Circulaire du 6 Mars 1998 relative à la féminisation des noms de métier, fonction, grade ou titre). O primeiro ministro Lionel Jospin reage à decisão de seu gabinete, na qual quatro mulheres desejavam ser chamadas de "Madame la Ministre". Dois relatórios, comandados pelo próprio ministro, chegam a conclusôes diferentes acerca da feminização da língua. De um lado, como mostra Elmiger (2011, p. 75), a Cogeter (Commission Générale de Terminologie et Néologie, 1998) aprova a feminização dos nomes dos trabalhos ou de profissóes para designar individualmente as mulheres, mas se opõe à utilização de nomes feminizados nos textos jurídicos, alegando que era necessário distinguir entre a designação de um indivíduo e a utilização de nomes comuns de pessoas para designar uma mudança oficial. De outro, a INaLF (Institut National de la Langue Française) publica um guia para ajudar a feminização (Femme, jécris ton nom, 1999), direcionado ao grande público, no qual a feminizaçáo geral do léxico é recomendada. Como a circular de 1986, o guia de 1999 se limita, como salienta Elmiger (2011, p. 75), a abordar essencialmente os aspectos lexicais da feminização. 
$\mathrm{Na}$ Bélgica francófona, a reflexão sobre a feminização da língua se concretiza em 1993, a partir do Decret du 21 Juin 1993 relatifà la féminsation des noms de métier, fonction, grade ou titre, publicado pelo Conseil de la Communauté Française. $\mathrm{O}$ decreto obrigava as instituiçôes subordinadas ao conselho a utilizarem termos femininos para designar as mulheres, mas ele não se pronuncia sobre que formas empregar. Essa lacuna, conforme Elmiger (2011, p. 75), é mais tarde preenchida a partir da publicação de uma ordem da Communauté Française, estabelecendo as regras de feminização dos nomes de profissóes, funçôes, graus e títulos. Os dois textos oficiais vêm de instâncias políticas: uma brochura destinada ao grande público, Mettre au féminin, que explica as regras morfológicas para formar o feminino a partir dos nomes masculinos correspondentes e Recommendations Génerales du Conseil Supérieur de Langue Française et Surtout une Liste de Noms de Métier, Fonction, Grade ou Titre. As regras sintáticas limitam-se, adverte Elmiger (2011, p. 75), a um conselho relativo aos determinantes, adjetivos e particípios, "concordar com o feminino". Quanto à feminização do discurso, as recomendações belgas são, para Emiger (2011, p. 75), bem sumárias: o guia sugere que "é recomendável não abusar do emprego genérico de nomes masculinos, mas não propôe soluçôes viáveis" ${ }^{\text {. }}$.

Por fim, na Suíça, em razão de seu federalismo, a questão da feminização é abordada em diferentes instâncias: federal, contonal e municipal. A Chancelaria Federal assim como os Serviços Linguísticos preocupam-se com a utilização de termos feminizados na escala nacional. Um grupo de trabalho interdepartamental publicou, em 1991, o relatório La Formulation non sexiste des textes legislatifs et administratifs. Esse relatório, escrito também em alemão e italiano, já que as autoridades procuram apresentar soluçóes aplicáveis a todas as línguas nacionais, não trata da feminização do léxico, mas da redação de texto, principalmente a redação de textos jurídicos e legislativos. A solução proposta, chamada de criativa, é a combinação de diferentes meios para evitar o emprego genérico de formas masculinas.

O Conselho Federal em 1993 decreta, de um lado, que o léxico e os documentos normativos devem ser feminizados e, de outro, que somente os "textos legislativos em alemão serão redigidos conforme a solução criativa, mas que a prática atual será mantida no que concerne aos textos em francês e italiano" (Chancellerie Fédérale, 1993, apud ELMIGER, 2011, p. 76) ${ }^{15}$.

14 "il est recommandé de ne pas abuser de l'emploi genérique des noms masculins, mais il ne propose pas de solutions viables" (ELMIGER, 2011, p. 75).

15 "seuls les texts législatifs en langue allemande seront rédigés conformément à la solution dite créative, mais que la pratique actuelle sera maintenue en ce qui concerne les textes français 
Na Suíça, como aponta Elmiger (2011, p. 76), a maioria das decisões relativas à feminização da língua é tomada em instância cantonal. Os distritos francófonos diferem consideravelmente quanto a seus compromissos no domínio da feminização, se alguns são muito ativos e tomam decisóes vinculadas para sua administração, outros não adotam nenhuma disposição particular. Duas publicaçôes são elaboradas: Dictionnaire féminin-masculin des professions, des titres e des fonctions (1990, reeditado em 1999) e o guia Écrire les genres: guide romand d'aide à la redation administrative et législative épicène.

\section{Um efeito de conclusáo}

As mulheres, durante séculos, serviram de espelho aos homens por possuirem o poder mágico e delicioso de refletirem uma imagem do homem duas vezes maior que o natural (WOOLF, 2004, p. 54)

Como buscamos mostrar neste texto, ao analisarmos o processo de manualização de uma linguagem não sexista, feminizada e suas condiçóes de produção, os manuais, legitimados pelo poder estatal, juntamente com a legislação produzida que os sustenta, funcionam como um espaço de dizer, atendendo a demandas que buscam sustentar uma posiçáo legitimada a mulheres, seja na sociedade ou nos usos que essa faz de uma língua. Como uma política linguística, os manuais ensinam e normatizam, de certo modo, a vida social, apontando o que pode ser dito e interditando o que náo pode, isto é, interdita-se o uso somente do masculino como genérico, apontando para a marcação do gênero feminino nos usos linguísticos. Esses manuais propóe uma equidade de que vai em direção a propostas de uma língua mais feminizada e menos masculinizada em que as profissóes, os cargos, as funçôes desenvolvidas pelas mulheres apareçam. Como instrumentos de diferentes intervençóes (principalmente por meio de leis), os manuais produzem um saber sobre o sexismo da linguagem, explicitando como, nas sociedades, sejam elas brasileira, espanhola ou belga (francesa), há ainda uma desigualdade quando se fala em gênero, quando se fala em homens e mulheres, em masculino e feminino. Assim, manualizar uma linguagem não sexista é fazer uso do gênero feminino quando as profissóes, funçôes, graus, títulos se referem às mulheres e, portanto, dar visibilidade na língua à mulher, ou seja, permitir que ela reflita sua própria imagem e não a do outro

et italiens" (apud ELMIGER, 2011, p. 76). 
(masculino).

\section{Referências}

ABBOU, J. L'antisexisme linguistique dans le brochures libertaires: pratiques d'écriture et métadiscours. Université de Provence. Aix-Marseille I, 2011. Disponível em: <https://tel.archives.ouvertes.fr/tel-00643802>. Acesso em: 08 out. 2018.

ALARIO, C.; BENGOECHEA, M.; CUNILL, E. L.; VARGAS, A. Nombra: la representación del femenino y el masculino en el lenguaje. Espanha: Gráficas Rodríguez, 1995.

AUROUX, S. Revolução tecnológica da gramatização. Campinas: Editora da Unicamp, 1992.

BEAUVOIR, S. O Segundo Sexo: A experiência vivida. Rio de Janeiro, RJ: Nova Fronteira, vol. 2, [1949] 1980.

BRASIL. Lei no 2.749, de 05 de abril de 1956. Dá norma ao gênero dos nomes designativos das funçóes públicas. Diário Oficial da Uniáo, Poder Executivo, Brasília, DF, 5 abr. 1956, p. 6457.

Projeto de lei do senado no 306, de 01 de setembro de 2005. Determina o uso da linguagem inclusiva para cargos na Administração Pública brasileira. Diário do Senado Federal, Poder Executivo, Brasília, DF, 01 set. 2005, p. 29541.

BECQUER, A-M.; CHOLEWKA, N. ; COUTIER, M. ; MATHIEU, M-J. ; CERQUIGLINI, B. Femme, j'écris ton nom. Guide d'aide à la féminisation des nomns de métiers, titres, grades et fonctions. Paris : Centre National de la Recherche Scientifique, Institut National de la Langure Française, 1999.

CUNILL, E. L. Guía del lenguaje para el ámbito educativo. Vitoria: 
EMAKUNDE/ Instituto Vasco de la mujer, 2008.

GARCIA, D. A.; SOUSA, L. M. A. A manualização do saber linguístico e a constituiçáo de uma linguagem não sexista. Revista Línguas \& Letras. Cascavel, v. 17, n. 35, p. 86-106, 2016.

GARCIA, D. A. Manualização de uma linguagem não sexista: uma política de equidade de gênero? In: SOARES, A. S. F.; GARCIA, D. A. (Org.). Inquietaçóes de Gêneros e sexualidades: leituras na contemporaneidade. Porto Alegre: Evangraf, 2017, p. 191-211.

GOVERNO DO ESTADO DO RIO GRANDE DO SUL. SECRETARIA DE POLÍTICAS PARA MULHERES. Manual para o uso não sexista da linguagem. O que bem se diz bem e entende. Rio Grande do Sul: Secretaria de Comunicação e Inclusão Digital, 2014.

ELMIGER, D. Féminisation de la langue française: une brève histoire des positions politiques et du positionnement linguistique. In: DUCHÊNE, A.; MOÏSE, C. (Eds.). Langage, genre et sexualité. Québec: Éditions Nota Bene, 2011.

IVÁÑEZ, M. P. L'influence de la planification linguistique dans la féminisation des titres en France et au Québec: deux résultats différentes en ce qui a trait à l'usage. Revue Québécoise de linguistique, v. 24, n. 2, p. 71-106, 1996.

LISPECTOR, C. A Hora da Estrela. Rio de Janeiro: José Olympio Editora, 1977.

ORLANDI, E. P. (Org.). História das idéias lingüísticas: construção do saber metalingüístico e constituição da língua nacional. Campinas: Pontes; Cáceres: Unemat, 2001.

Análise de Discurso: princípios e procedimentos. Campinas: Pontes, 2002. 
PÊCHEUX, M. Semântica e discurso. Uma crítica à afirmação do óbvio. Campinas: Editora da Unicamp, 1997.

PERUSSO, M. Por uma sociedade inclusiva. GOVERNO DO ESTADO DO RIO GRANDE DO SUL. SECRETARIA DE POLÍTICAS PARA MULHERES. Manual para o uso náo sexista da linguagem. $O$ que bem se diz bem e entende. Rio Grande do Sul: Secretaria de Comunicação e Inclusão Digital, 2014.

PUECH, C. Manuélisation et disciplinarisation des savoirs de la langue. Lénonciation. Les Carnets du Cediscor, 1998. Disponível em : <http:// cediscor.revues.org/267>. Acesso em: 01 fev. 2015.

RIO GRANDE DO SUL. Decreto no 49.994, de 27 de dezembro de 2012. Estabelece a utilização da linguagem inclusiva de gênero nos atos normativos, nos documentos e nas solenidades do Poder Executivo Estadual. Diário Oficial do Estado, Rio Grande do Sul, RS, no 248, 28 dez. 2012, s.p.

Decreto no 49.995, de 27 de dezembro de 2012. Institui Grupo de Trabalho com a finalidade de discutir e propor medidas para a utilização da linguagem inclusiva de gênero nos atos normativos, nos documentos e nas solenidades do Poder Executivo Estadual. Diário Oficial do Estado, $\mathrm{n}^{\circ}$ 248, 28 dez. 2012, s.p.

Lei no 14.489 , de 30 de janeiro de 2014. Dispóe sobre a utilização da linguagem inclusiva de gênero no âmbito da Administração Pública Estadual. Diário Oficial do Estado, no 022, 31 jan. 2014, s.p.

WOOLF, V. Um teto todo seu. 2. ed. Rio de Janeiro: Nova Fronteira, 2004.

ZOPPI-FONTANA, M. G. Língua oficial e políticas públicas de equidade de gênero. Línguas e instrumentos linguísticos. Campinas, $n^{\circ} 36$, julho/ dezembro, p. 221-243, 2015. 